\title{
Tarım Fuarlarına Katılan Firmaların Bakış Açısıyla Fuar Organizasyonları ve Yöre Ekonomisine Katkıları: Milas 2. Güney Ege Tarım Fuarı Örneği
}

\author{
Tayfun ÇUKUR $^{1^{*}} \quad$ Figen ÇUKUR ${ }^{2}$ \\ ${ }^{1}$ Muğla Sıtkı Koçman Üniversitesi Milas MYO, Pazarlama ve Reklamcılık Bölümü, Milas-Muğla, \\ ${ }^{2}$ Muğla S1tkı Koçman Üniversitesi Milas MYO, Yönetim ve Organizasyon Bölümü, Milas-Muğla, \\ (*Sorumlu yazar e-mail: tayfunc@ mu.edu.tr)
}

Geliş Tarihi : 26.05.2017

Kabul Tarihi : 07.09.2017

\begin{abstract}
ÖZET: Bugün artık enformasyon, çiftçiler için önemli bir tarımsal girdi niteliği taşımaktadır. Tarımsal yayım sayesinde çiftçiler ihtiyaç duydukları enformasyona kolayca ulaşabilmektedirler. Kırsal alanda çiftçilere tarımsal enformasyon sağlayan çok sayıda kuruluş bulunmaktadır. Bunlar arasında, tarım il ve ilçe müdürlükleri, üniversiteler, kooperatifler, birlikler, araştırma kuruluşları, danışmanlık şirketleri sayılabilir. Çiftçiler tarımsal girdi ve ürün pazarlayan firmalardan da önemli tarımsal enformasyonlar elde edebilmektedirler. Konuya bu açıdan bakıldığında çeşitli tarım fuarlarına katılan firmalar çiftçilere enformasyon sağlayarak önemli tarımsal etkinlik gerçekleștirmektedir. Bu bağlamda tarım fuarlarında firma temsilcileri ile çiftçiler bir araya gelmekte ve karşılıklı enformasyon transferi gerçekleşmektedir. Bu araştırmada Milas 2. Güney Ege Tarım Fuarı örnek olay olarak incelenmiş ve fuara katılan 51 firma ile anket çalışması gerçekleştirilmiştir. Fuara katılan tüm firma temsilcilerinin fuar süresince standlarını ziyaret eden kişilere gerek firmaları gerekse fuardaki ürünleriyle ilgili enformasyon sağladıkları tespit edilmiştir. Fuar dışı zamanlarda da üreticilere enformasyon sağladığını belirten firma oranı ise \%88.2 olarak saptanmıştır. Tarım fuarları çiftçilere enformasyon sağlayan önemli etkinlikler olduğundan çiftçilerin bu fuarlara katılımları teşvik edilmelidir.
\end{abstract}

Anahtar kelimeler: Fuar, tarım, enformasyon, Milas.

\section{Fair Organizations From The Participating Firms in the Agricultural Fairs Perspective and Its Contributions on the Local Economy: The Case of Milas 2. South Aegean Agricultural Fair}

\begin{abstract}
Today information is an important agricultural input for farmers. Thanks to agricultural extension, farmers can have access to the information which they need. There are numerous organizations that provide agricultural information to farmers in rural areas. Among them, the provincial and district directorates of Agriculture, universities, cooperatives, unions, research organizations, consulting companies include. Farmers can get important agricultural information, from companies which sell agricultural inputs and agricultural product. From this perspective, agricultural fairs are important agricultural activities that providing information for farmers. In agricultural fairs farmers and company representatives coming together and the transfer of mutual information are realized. In this study Milas 2. South Aegean Agricultural Fair was examined as a case study and 51 firms attending the fair were interviewed. It was determined that representatives of all the firms during the fair provide information about both companies and their products to people who visiting the fair stands. It was determined that rate of firm which provides information to farmers of non-fair times was $88.2 \%$. Since agricultural fairs are important events providing information to farmers, participating in these fairs of farmers should be encouraged.
\end{abstract}

Keywords: Fair, agriculture, information, Milas.

\section{GíRiş}

Günümüzde enformasyon, bir kaynak veya girdi olarak görülmektedir (Cinemre ve Demiryürek, 2005). Tarım, özellikle yeni enformasyonun önemli olduğu bir alandır. Çünkü enformasyon, çiftçilerin hem kendilerinin sosyo-ekonomik hem de tarımsal ve ekolojik çevrelerindeki değişikliklerle karşılaştıklarında, kendi üretim sistemleriyle ilgili daha iyi karar vermelerine olanak tanımaktadır (Demiryürek, 2001). Çiftçiler tarımsal faaliyetlerini yürütürken birçok kaynaktan enformasyon elde etmektedirler. Genel olarak bir değerlendirme yapıldığında Gıda Tarım ve Hayvancılık Bakanlığı il ve ilçe müdürlükleri çiftçiler için önemli bir enformasyon kaynağı durumundadır. Çiftçilere enformasyon sağlayan diğer kişi ve kuruluşlar arasında, çiftçilerin diğer aile üyeleri, arkadaş ve akrabaları, ilaç, gübre ve tohum bayileri, çiftçilerin ürünlerini satın alan firmalar, kooperatif ve birlikler, tarım danışmanları, üniversiteler, araştırma kuruluşları ve yazılı ve görsel medya kuruluşları sayılabilir.

Fuar, ticaretle ilgili ürün ya da hizmetlerin, teknolojik gelişmelerin, bilgi ve yeniliklerin tanıtımı, pazar bulunabilmesi ve satın alınabilmesi, teknik işbirliği, geleceğe yönelik ticari ilişki kurulması ve geliştirilmesi için, belirli bir takvime bağlı olarak, düzenli aralıklarla genellikle de aynı yerlerde gerçekleştirilen bir tanıtım etkinliğidir (Ünsaldı, 2007). Günümüzde düzenlenen ticari fuarların, özellikle de üreticilerin ve aracıların katıldığı iş fuarlarının önemi yadsınamaz (Demirci ve Arslaner, 2012). Fuar organizasyonları sadece organizatör firmalar ya da katılımcı firmalar açısından değil, aynı zamanda düzenlendikleri kent, bölge hatta ülkeler için olumlu sonuçlar doğurmakta, yöre halkının sosyal ve kültürel gelişimlerine önemli katkılarda 
bulunmaktadırlar (Torun et al., 2012). Fuar organizasyonları şehirlerin birer destinasyon olarak pazarlanmasında ve imaj oluşturma çabalarında önemli bir ișlev üstlenmektedir. Şehirlerin var olan kültürlerini ve kimliklerini açı̆̆a çıkarması ve fuar, kongre gibi organizasyonlara ev sahipliği yapması imaj oluşturma çabalarının tüketicilerin gözündeki değere dönüşmesine olanak tanıyan bir unsur olarak değerlendirilebilir (Avan et al., 2016).

Fuar ve sergiler en eski pazarlama araçlarından biridir (Varga, 2009). Fuarlar, festivaller ve şenlikler, malların ve hizmetlerin tanıtılması için yapılan ve bir takım sosyal ve kültürel faaliyetleri içeren düzenlemelerdir (Sarı, 2016). Ticari fuar katılımları işletmeler tarafindan; mevcut ve potansiyel müşterilere işletmenin ürünleri konusunda bilgi vermek, yeni müşteri portföyü oluşturmak, müşterilerin dikkatini çekmek, arzu ve istek uyandırmak, ürünü satmak, aracılarla işbirliği yapmak, hem rakiplerin hem de müşterilerin gözünde işletme imajını geliştirmek veya tazelemek gibi amaçlarla gerçekleştirilebilir (Arl1, 2012).

Fuarlar sırasında firmalar iş bağlantıları kurmakta ürünlerini tanıtmakta, piyasa ve pazar hakkında enformasyon temin etmekte, müşteri ihtiyaçlarını analiz etmekte ve rakip firmaların ürün ve teknolojileri hakkında fikir sahibi olmaktadırlar. Fuarlar, üst seviyede iletişim imkanı sağlayan önemli bir tanıtım aracıdır. İletişim süreci, taraflar arasında bilgi ve haberlerin değişim sürecini içermekte olup fuarlar da bu iletişim sürecinin bir parçasıdır (Aycı, 2011). İhtisas fuarları niteliğindeki tarım fuarlarında, çiftçiler ilaç, gübre ve tohum bayileri ve çiftçilerin ürünlerini satın alan firma temsilcileri ile iletişim kurmakta ve fuarlarda karşılıklı bir enformasyon transferi gerçekleşmektedir. Yeni ürünler ve yeni teknolojilerin sergilendiği ve çiftçi ve firmaların buluştuğu tarım fuarlarına çiftçilerin ziyaretleri oldukça önemlidir.

Çiftçiler tarım fuarlarında tarımdaki teknolojik gelişmeler (tarımsal ürün ve tarımsal girdilerdeki) ve tarım sistemleri (organik tarım, iyi tarım uygulamaları, entegre ürün yönetimi vb.) hakkında bilgi sahibi olmaktadır. Çiftçiler fuar süresince düzenlenen çeşitli yarışmalar sayesinde bilgilerini güncelleme imkanına kavuşmaktadır.

Çiftçiler fuarlarda oluşturulan demonstrasyon alanları sayesinde yeni teknolojiyi anında uygulama imkanına sahip olmaktadır. Çiftçiler özellikle tarımsal mekanizasyon ile ilgili alet, ekipman ve makineleri toplu olarak görebilmekte, bu da çiftçilere farklı alternatifleri karşılaştırma imkanı sağlamaktadır.

Fuarlar çiftçiler için sosyal bir ortam yaratmaktadır. Fuar süresince çiftçiler arası bir iletişim de gerçekleşmekte, çiftçiler görüş, deneyim, beklenti ve sorunlarını paylaşma imkanı yakalamaktadır. Diğer taraftan çiftçiler fuar süresince düzenlenen bilimsel etkinlikler (seminer, panel vb.) sayesinde araştırma kuruluşları, yayım kuruluşları ve üniversitelerin personelleriyle bir araya gelme imkanına kavuşmaktadır.

Fuara katılan üreticiler ürün satın alırken fuara özel satış kampanyalarından yararlanma imkanına sahip olabilmektedir. Çiftçilerin stand ziyaretleri sırasında topladıkları çeşitli broşür ve kitapçıklar tarımsal üretim sürecinde başvurdukları önemli bir kaynak niteliğindedir (Çukur, 2013).

Milas ilçesinde tarım fuarlarının geçmişi 2010 yılına dayanmaktadır. 2010 yılında tarım fuarının ilki düzenlenmiş olup, Milas 2. Güney Ege Tarım Fuarı ise 3-6 Mart 2011 tarihleri arasında Milas'ta gerçekleştirilmiştir. Fuara tarım teknolojileri, tarımsal mekanizasyon, hayvancılık teknolojileri, hayvan sağlığı, yem, tohum, fidancılık, sulama, gıda ve gida endüstrisi ve ambalaj imalatı ve pazarlamasıyla uğraşan firmalar başta olmak üzere toplam 178 firma katılmıştır. Fuar kapsamında ayrıca zeytinyağı yarışması, kadın çiftçi yarışması ve bitkisel ve hayvansal üretim konulu bir panel düzenlenmiştir.

$\mathrm{Bu}$ çalışmada temel amaç, Milas 2. Güney Ege Tarım Fuarı'na katılan firmaların genel profilini ortaya koymak, firmaların fuar süresince yaptıkları etkinlikleri belirlemek, firmaların tarım fuarlarıyla ilgili görüşlerini saptamak ve firmaların fuar anında ve fuar dışı zamanlarda üreticilere hangi konularda enformasyon sağladığını tespit etmektir.

\section{MATERYAL VE METOT}

Araştırmanın ana materyalini, Muğla ili Milas ilçesinde ikincisi düzenlenen Milas 2. Güney Ege Tarım Fuarı'na katılan firmaların temsilcileriyle yüz yüze görüşme yoluyla elde edilen veriler oluşturmaktadır. Tariş Çırçır Fabrikasında, 5.500 metrekare kapalı alanda düzenlenen fuara 178 firma katılmıştır (Anonim, 2011). Bu ana kitleye dayalı olarak da örnek hacmi Eşitlik (1) deki oransal örnek hacmi formülüyle hesaplanmıştır (Newbold 1995). En yüksek örnek hacmine ulaşabilmek amacıyla, fuar dişı zamanlarda üreticiye enformasyon sağlayan firma oranı $\% 50$ ve sağlamayanların oranı $\% 50$ kabul edilmiştir. Aşağıdaki formül yardımıyla \%90 önem düzeyinde, $\% 10$ hata payı ile örnek hacmi 49.2 bulunmuştur. 0.2 kişiyle anket yapılamayacağından bu sayı 50'ye tamamlanmıştır. Araştırmada örnek hacminin \%10 fazlası kadar anket yapılmış olup toplam 55 anket uygulanmıştır. Yapılan anketlerin 4'ünde eksik bilgi bulunması ve yarım bırakılması gibi nedenlerle 51 anket araştırmaya dahil edilmiştir.

$$
\mathrm{n}=\frac{N p(1-p)}{(N-1) \sigma_{p x}^{2}+p(1-p)}
$$


Bu eşitlikte;

$\mathrm{n}$ : Toplam görüşülecek firma sayısı

$\mathrm{N}$ : Fuara katılan toplam firma sayısı

p: Fuar dışı zamanlarda üreticiye enformasyon sağlayan firma oranı (0.50)

(1-p): Fuar dişı zamanlarda üreticiye enformasyon sağlamayan firma oranı (0.50)

$\sigma_{p x}^{2}: \quad$ Oranın varyansıdır $(\alpha=0.10$ için $\sigma_{p}=0.06079$ ).

Verilerin analizlerinde ortalamalar ve yüzde hesapları yanında firma temsilcilerinin fuarın firmalarına ve üreticiye/yöreye katkıları ile ilgili tutum değişkenlerinin ölçümü için beşli likert ölçeği kullanılmıştır. Elde edilen sonuçlar çizelge halinde özetlenmiş ve yorumlanarak değerlendirilmiştir.

\section{BULGULAR VE TARTIŞMA}

\section{Firmaların Genel Yapısı ve Firma Temsilcilerinin Özellikleri}

Bu bölüm başlığı altında, fuara katılan firmalar ve firma temsilcileri hakkında genel bilgiler verilmiştir. Bu kapsamda firmaların hukuki şekilleri, kuruluş tarihi, faaliyet alanları ile birlikte fuara katılan firma temsilcilerinin eğitim düzeyleri incelenmiştir. Buna göre incelenen firmaların \%39.2'si limited şirket, \%33.3'ü şahıs şirket, \%25.5'i anonim şirket ve 1 işletme de kollektif şirket statüsündedir.

Firmaların faaliyet alanıyla ilgili deneyimleri incelendiğinde, firmaların ortalama faaliyet süreleri 17.4 yıl olarak saptanmıştır. Firmaların en eskisi 58, en yenisi 1 yıl önce kurulmuştur. Firmaların \%36.7'si 1953-1990 döneminde, \%28.6's1 1991-2000 döneminde ve \%34.7'si da 2001 sonrası dönemde kurulmuştur. 2 firmadan kuruluş tarihi ile ilgili bilgi alınamamıştır.

Araştırmaya katılan firmaların \%54.9'unun yurt içinde, \%19.6'sının ise yurtdışında temsilcilikleri bulunmaktadır. İhracat yapan firma oranı \%37.3'dür. Firmalarda istihdam edilen ortalama personel sayıs1 52.55 olarak tespit edilmiştir.

Araştırmaya katılan firmaların \%27.5'inin başlıca faaliyet alanının tarımsal alet ve makine imalat ve pazarlaması olduğu belirlenmiştir. Firmaların \%23.5'inin ise başlıca faaliyet alanı tarımsal ürün ticaretidir. Firmaların $\% 9.8^{\prime} \mathrm{i}$ ise tarımsal gübre ve tarımsal ilaç pazarlaması faaliyetlerini sürdürmektedir (Çizelge 1).

Çizelge 1. Firmaların başlıca faaliyet alanları

\begin{tabular}{|c|c|c|}
\hline Faaliyet alanı & $\mathbf{n}$ & $\%$ \\
\hline Tarımsal alet ve makine imalat ve pazarlaması & 14 & 27.5 \\
\hline Tarımsal ürün ticareti & 12 & 23.5 \\
\hline Tarımsal gübre ve tarımsal ilaç pazarlaması & 5 & 9.8 \\
\hline Tohum pazarlama & 4 & 7.8 \\
\hline Ar1 ve ar1 ürünleri ticareti & 4 & 7.8 \\
\hline Süt sağım makinesı imalat ve pazarlama & 3 & 5.8 \\
\hline Fide fidan yetiştiriciliği ve pazarlaması & 2 & 3.8 \\
\hline Paslanmaz çelik tank imalatı & 1 & 2 \\
\hline Ambalaj & 1 & 2 \\
\hline Halıcılik & 1 & 2 \\
\hline Sulama sistemleri & 1 & 2 \\
\hline Demir profil saç işleme & 1 & 2 \\
\hline Hayvan yemi pazarlaması & 1 & 2 \\
\hline Balıkçılık & 1 & 2 \\
\hline Toplam & 51 & 100.0 \\
\hline
\end{tabular}

Araştırmaya katılan firma temsilcilerinin yaş ortalaması 37.8 olarak belirlenmiştir. Eğitim durumları incelendiğinde firma temsilcilerinin \%5.9'unun yüksek lisans, \%51'inin üniversite, \%29.4'ünün lise, \%7.8'inin ortaokul ve \%5.9'unun ilkokul mezunu olduğu belirlenmiştir.

\section{Firma Temsilcilerinin Organizasyonuna İlişkin Görüşleri}

Fuar

Araştırmaya katılan firmaların \%78.4'ünün tarım fuarlarına, \%35.3'ünün ise uluslararası ticaret fuarlarına daha önce katıldıkları tespit edilmiştir. I. Milas Tarım Fuarına katılan firma oranı ise \%54.9 olarak bulunmuştur. I. Milas Tarım Fuarına katılan firmaların \%92.9'u, fuarın firma tanıtımına ve satışlara olumlu katkısının olduğunu düşünmektedirler.

Milas 2. Güney Ege Tarım Fuarı'na katılan firmaların \%98'i fuarın firma tanıtımına ve satışlara olumlu katkısının olacağını düşünmektedir. Sadece 1 firma aksi yönde görüş bildirmiştir. Torun et al. (2012) tarafindan yapılan araştırmada, fuara katılan 

Örneği

işletmecilerin \%63.2'sinin bu tür fuarları yararlı bulduğu belirlenmiştir. Araştırmaya katılan firmalar, standlarını günde ortalama 474.8 kişinin ziyaret ettiğini belirtmișlerdir.

Fuara katılan tüm firma temsilcilerinin fuar süresince standlarını ziyaret eden kişilere gerek firmaları gerekse fuardaki ürünleriyle ilgili enformasyon sağladıkları tespit edilmiştir. Bunun yanında firmaların \%38.5'inin fuar sürecince broșür dağıtımı, \%29.9'unun ürün satışı ve \%13.6'sının ise promosyon ürünlerin dağıtımı faaliyetlerini gerçekleştirdikleri belirlenmiştir (Çizelge 2).

Çizelge 2. Firmaların fuar süresince yaptıkları etkinlikler

\begin{tabular}{|l|c|c|}
\hline Etkinlik adı & n & \% \\
\hline Broşür dağıtımı & 45 & 38.5 \\
\hline Ürün satışı & 35 & 29.9 \\
\hline Promosyon ürünlerin dağıtımı & 16 & 13.6 \\
\hline Video ile firma/ürün tanıtımı & 14 & 12.0 \\
\hline Ürün ikramı & 7 & 6.0 \\
\hline TOPLAM & $117^{*}$ & 100.00 \\
\hline
\end{tabular}

*Birden fazla yanıt alınmıştır.

Fuar dışı zamanlarda da üreticilere enformasyon sağladığını belirten firma oranı ise \%88.2 olarak saptanmıştır. Firma temsilcilerine üreticilere hangi konularda enformasyon sağlandığı sorulmuş, alınan cevaplara göre Çizelge 3 oluşturulmuştur. Firmaların $\% 29.1$ 'inin üreticilere tarımsal girdi kullanımı, $\% 28.2$ 'si üretim tekniği ve \%17.4'ü de hasat ile ilgili konularda enformasyon sağladığını belirtmiştir. Tarım firmalarından üreticilere enformasyon transferi, genel olarak iki şekilde gerçekleşmektedir. Üreticiler tarım firmalarını ziyaret ettiklerinde firmalar, ilgili ürün ve diğer tarımsal konularda üreticileri enforme etmektedir. Diğer taraftan firmalar ürünlerini tanıtmak amacıyla köylerde tanıtım faaliyetleri de gerçekleştirmektedir. $\mathrm{Bu}$ tanıtım faaliyetleri genellikle köy kahvelerinde yapılmaktadir.
Çizelge 3. Firmaların üreticilere sağladıkları enformasyon konuları

\begin{tabular}{|l|c|c|}
\hline Konular & $\mathbf{n}$ & $\mathbf{\%}$ \\
\hline Tarımsal girdi kullanımı & 30 & 29.1 \\
\hline Üretim tekniği & 29 & 28.2 \\
\hline Hasat & 18 & 17.4 \\
\hline Pazarlama & 15 & 14.6 \\
\hline Finansman & 4 & 3.9 \\
\hline Tarım sigortası & 4 & 3.9 \\
\hline Hastalık ve zararlılar & 2 & 1.9 \\
\hline Halıcı1ı & 1 & 1 \\
\hline TOPLAM & $103^{*}$ & 100.0 \\
\hline
\end{tabular}

*Birden fazla yanıt alınmıştır.

Araştırmaya katılan firmaların \%62.7'sinde (32 firma) araştırma geliștirme (Ar-Ge) faaliyetlerinin olduğu tespit edilmiştir. Ar-Ge faaliyetleri olan firmalara faaliyetlerin niteliği sorulmuş ve Çizelge 7 oluşturulmuştur. Firmaların \%37.1'inin ürün geliştirme, \%32.9'unun teknoloji geliştirme ve \%30'unun ise ürün iyileştirmeye yönelik çalışmaları bulunmaktadır (Çizelge 4).

Çizelge 4. Firmaların Ar-Ge faaliyetlerinin niteliği

\begin{tabular}{|l|c|c|}
\hline Faaliyetlerin niteliği & n & \% \\
\hline Ürün geliştirme & 26 & 37.1 \\
\hline Tekonoloji geliştirme & 23 & 32.9 \\
\hline Ürün iyileştirme & 21 & 30.0 \\
\hline TOPLAM & $70^{*}$ & 100.0 \\
\hline
\end{tabular}

*Birden fazla yanıt alınmıştır.

Çizelge 5'de fuarın firmaya katkıları ile ilgili firma temsilcisi görüşlerine yer verilmiştir. Firma temsilcilerine göre, fuarın firmaya en önemli katkısı yeni ürünlerin tanıtım imkanını sağlamasıdır (4.31). Diğer önemli katkılar, yeni teknolojilerin tanıtımını sağlaması (4.10) ve geniş bir müşteri kitlesine ulaşma imkanı sağlamasıdır (4.06). 
Çizelge 5. Fuarın firmaya katkıları ile ilgili firma temsilcileri görüşleri

\begin{tabular}{|l|c|c|c|c|c|c|c|c|c|c|c|c|}
\hline Görüşler & $\mathbf{1}$ & $\mathbf{\%}$ & $\mathbf{2}$ & $\mathbf{\%}$ & $\mathbf{3}$ & $\mathbf{\%}$ & $\mathbf{4}$ & $\mathbf{\%}$ & $\mathbf{5}$ & $\mathbf{\%}$ & Toplam & $\begin{array}{c}\text { Ölçek } \\
\text { Ortalaması }\end{array}$ \\
\hline $\begin{array}{l}\text { Yeni ürünlerin } \\
\text { tanıtım imkanını } \\
\text { sağlar. }\end{array}$ & 1 & 2 & 2 & 3.9 & 4 & 7.9 & 17 & 33.3 & 27 & 52.9 & 51 & 4.31 \\
\hline $\begin{array}{l}\text { Yeni } \\
\text { teknolojilerin } \\
\text { tanıtımını sağlar. }\end{array}$ & 2 & 3.9 & 1 & 2.0 & 6 & 11.8 & 23 & 45.1 & 19 & 37.2 & 51 & 4.10 \\
\hline $\begin{array}{l}\text { Geniş bir müşteri } \\
\text { kitlesine ulaşma } \\
\text { imkanı sağlar. }\end{array}$ & 1 & 2.0 & 1 & 2.0 & 14 & 27.4 & 13 & 25.5 & 22 & 43.1 & 51 & 4.06 \\
\hline $\begin{array}{l}\text { Doğrudan satı̧a } \\
\text { imkan verir. }\end{array}$ & 2 & 3.9 & 5 & 9.8 & 8 & 15.7 & 14 & 27.5 & 22 & 43.1 & 51 & 3.96 \\
\hline $\begin{array}{l}\text { Ürünün iç ve dış } \\
\text { pazarlamasına } \\
\text { katkıda bulunur. }\end{array}$ & - & - & 2 & 3.9 & 15 & 29.4 & 23 & 45.1 & 11 & 21.6 & 51 & 3.84 \\
\hline $\begin{array}{l}\text { Ürün/ikili ticari } \\
\text { antlaşmalarının } \\
\text { yapılmasına } \\
\text { olanak verir. }\end{array}$ & 4 & 7.8 & 3 & 5.9 & 9 & 17.6 & 21 & 41.2 & 14 & 27.5 & 51 & 3.75 \\
\hline $\begin{array}{l}\text { Rakipler ile fikir } \\
\text { alışverişi sağlar. }\end{array}$ & 6 & 11.8 & 7 & 13.7 & 6 & 11.8 & 20 & 39.2 & 12 & 23.5 & 51 & 3.49 \\
\hline
\end{tabular}

1.Hiç katılmıyorum 2.Kısmen katılıyorum 3.Orta derecede katılıyorum 4.Katılıyorum 5.Tamamen katılıyorum

Çizelge 6'da fuarın üreticiye/yöreye katkıları ile ilgili firma temsilcisi görüşlerine yer verilmiştir. Firma temsilcilerine göre fuarın üreticiye/yöreye en önemli katkısı, fuarın bölge üreticisinin yeni teknolojilerden ve tarımsal yeniliklerden haberdar olmasını sağlamasıdır
(4.67). Diğer önemli katkılar, yörenin ve yöresel ürünlerin tanıtımı ve markalaşmasını sağlaması (4.33) ve bölge üreticisinin pazarlama ve satış potansiyelini arttırmasıdır (4.24).

Çizelge 6. Fuarın üreticiye/yöreye katkıları ile ilgili firma temsilcileri görüşleri

\begin{tabular}{|l|c|c|c|c|c|c|c|c|c|c|c|c|}
\hline Görüşler & $\mathbf{1}$ & $\mathbf{6}$ & $\mathbf{2}$ & $\mathbf{\%}$ & $\mathbf{3}$ & $\mathbf{\%}$ & $\mathbf{4}$ & $\mathbf{\%}$ & $\mathbf{5}$ & $\mathbf{\%}$ & Toplam & $\begin{array}{c}\text { Ölçek } \\
\text { Ortalaması }\end{array}$ \\
\hline $\begin{array}{l}\text { Bölge üreticisinin } \\
\text { yeni } \\
\text { teknolojilerden ve } \\
\text { tarımsal } \\
\text { yeniliklerden } \\
\text { haberdar olmasını } \\
\text { sağlar. }\end{array}$ & - & - & - & 2 & 3.9 & 13 & 25.5 & 36 & 70.6 & 51 & 4.67 \\
\hline $\begin{array}{l}\text { Yörenin ve } \\
\text { yöresel ürünlerin } \\
\text { tanıtımı ve } \\
\text { markalaşmasını } \\
\text { sağlar. }\end{array}$ & 1 & 2.0 & - & - & 6 & 11.7 & 18 & 35.3 & 26 & 51.0 & 51 & 4.33 \\
\hline $\begin{array}{l}\text { Bölge üreticisinin } \\
\text { pazarlama ve satış } \\
\text { potansiyelini } \\
\text { arttırır. }\end{array}$ & - & - & 1 & 2.0 & 9 & 17.6 & 18 & 35.3 & 23 & 45.1 & 51 & 4.24 \\
\hline $\begin{array}{l}\text { Tarımsal } \\
\text { konularda yeni iş } \\
\text { fikirlerinin } \\
\text { üretilmesine } \\
\text { olanak sağlar. }\end{array}$ & 1 & 2.0 & - & - & 6 & 11.7 & 18 & 35.3 & 26 & 51.0 & 51 & 4.20 \\
\hline $\begin{array}{l}\text { Yeni yatırım } \\
\text { alanlarına imkan } \\
\text { verir. }\end{array}$ & 3 & 5.9 & 3 & 5.9 & 9 & 17.6 & 17 & 33.3 & 19 & 37.3 & 51 & 3.90 \\
\hline
\end{tabular}

1.Hiç katılmıyorum 2.Kısmen katılıyorum 3.Orta derecede katılıyorum 4.Katılıyorum 5.Tamamen katılıorum 


\section{SONUÇ VE ÖNERILER}

Milas 2. Güney Ege Tarım Fuarı'na katılan firmaların \%98'i fuarın firma tanıtımına ve satışlara olumlu katkısının olacağını düşünmektedir. Fuara katılan tüm firma temsilcilerinin fuar süresince standlarını ziyaret eden kişilere gerek firmaları gerekse fuardaki ürünleriyle ilgili enformasyon sağladıkları tespit edilmiştir. Fuar dışı zamanlarda da üreticilere enformasyon sağladığını belirten firma oranı ise \%88.2 olarak saptanmıştır. Firma temsilcilerine göre, fuarın firmaya en önemli katkısı yeni ürünlerin tanıtım imkanını sağlamasıdır. Diğer önemli katkılar, yeni teknolojilerin tanıtımını sağlaması ve geniş bir müşteri kitlesine ulaşma imkanı sağlaması olarak bulunmuştur. Firma temsilcilerine göre fuarın üreticiye/yöreye en önemli katkısı, fuarın bölge üreticisinin yeni teknolojilerden ve tarımsal yeniliklerden haberdar olmasını sağlamasıdır. Tarım fuarlarının etkinliklerinin artması, yöreye ve üreticilere daha fazla katkıda bulunabilmesi için alınması gereken tedbirler ve dikkat edilmesi gereken bazı konular bulunmaktadır:

-Öncelikle fuarların tanıtımları çok iyi yapılmalıdır. Gerek yerel firmaların gerekse üreticilerin fuarlardan haberdar edilmeleri sağlanmalıdır. Fuarlar ihtisas fuarları halini almalı ve fuarlara sadece fuarla ilgisi olan ziyaretçilerin katılmaları sağlanmalıdır. Diğer taraftan, fuarlara fuar konusu dışında faaliyet gösteren firmaların katılımı da engellenmelidir.

-Yörelerde fuar alanları oluşturulmalı, yerel halk fuarlar konusunda bilinçlendirilmeli ve fuarların devamlılığı sağlanmalıdır. Fuar alanlarının şehir merkezlerine yakın olmasına dikkat edilmelidir.

-Fuar zamanlaması da önemli bir diğer konudur. Fuarlar tarımsal faaliyetlerin yoğun olduğu dönemlerden ziyade hasat sonrası dönemde düzenlenmelidir.

-Fuara katılan rakip firmaların standlarının yan yana olmasına dikkat edilerek, üreticilerin ürünler hakkında daha kolay kıyaslama yapması sağlanmalıdır.

-Fuarlarda panel ve konferanslar düzenlenmeli, fuarlarda uygulama ve demonstrasyon alanları oluşturulmalıdır.
-Fuar organizasyonuna gereken önem verilmedir. Fuarlarda gerek katılımcı firmaların gerekse ziyaretçilerin tuvalet, yiyecek ve içecek ihtiyaçları karşılanmalı bu konularda hijyene gereken hassasiyet gösterilmelidir. Fuara katılan firmalara internet hizmeti sunulmalı, fuar salonundaki ses ve 1şık sistemine özen gösterilmedir (Çukur, 2013).

\section{KAYNAKLAR}

Arl1, E., 2012. Deniz turizm endüstrisinde faaliyet gösteren işletmelerin fuarlara katılım amaçlarının firma performansı ile ilişkisi, Seyahat ve Otel İşletmeciliği Dergisi 9(3): 25-37.

Avan, A., Zorlu, Ö. Baytok, A., 2016. Fuar organizatörlerinin bakış açısıyla fuar organizasyonlarının belirleyicileri ve yaşanan sorunlar, The Journal of Academic Social Science: 37: .216-230.

Ayc1, A., 2011. Pazarlama karması açısından yurtdışı fuarlar: kosgeb yurtdışı fuar desteklerinden faydalanan kobi'lere yönelik bir araştırma, Gazi Üniversitesi İktisadi ve İdari Bilimler Fakültesi Dergisi 13(3): 159-182.

Anonim, 2011. Ege Bölgesi'nin en büyük gıda tarım ve hayvancılı fuarı açıldı. Available:http://www.muglatarim.gov.tr/indexx.php?l=1\&sayfa_id=333\&g_id=15529\&i $\mathrm{d}=32275$.

Newbold, P., 1995. Statistics for Business and Economics, Prentice Hall Inc., USA, Pages 1016.

Cinemre, H. A., Demiryürek, K., 2005. Tarımsal Yayım ve Haberleşme, Ondokuz Mayıs Üniversitesi Ziraat Fakültesi Ders Kitabi No:17, 157s., Samsun.

Çukur, T., 2013. The Importance of the participation to agricultral fairs for farmers, The Journal of Ege University Faculty of Agriculture, Special Issue, Volume I, p.261-264.

Demirci, B., Arslaner, E., 2012. Fuar organizasyonlarının yerel ekonomiye ve tekrar gelme niyetine etkileri: Bursa Örneği, Sosyal ve Beşeri Bilimler Dergisi 4(2): 63-73.

Demiryürek, K., 2001. Tarımsal Enformasyon ve Bilgi Sistemleri Üzerine Bir Araştırma: Kavram, Teori ve Metot Rehberi, Türkiye Ziraat Odaları Birliği Yayın No: 218, 62s., Ankara.

Sarı, C., 2016. Antalya'da fuarlar, festivaller ve yayla şenliklerinin alternatif turizmin gelişmesindeki rolü, Mehmet Akif Ersoy Üniversitesi Sosyal Bilimler Enstitüsü Dergisi 8 (15): 95111

Torun, E., Çelik, A., Bobat, A., 2012. Pazarlamada fuarların rolü ve önemi (Yalova Süs Bitkileri İhtisas Fuarı Örneği), Kahramanmaraş Sütçü İmam Üniversitesi Doğa Bilimleri Dergisi, 15(2): 11-21.

Ünsaldı, M., 2007. Fuarcılık ve Türkiye'de Fuarcılıkla İlgili Faaliyetler, Doğu Anadolu Bölgesi Araştırmaları, 153-156.

Varga, L., 2009. Kava model testing on agricultural exhibitions, 4th Aspects and Visions of Applied Economics and Informatics, p. 396-404. March 26 - 27, Debrecen, Hungary. 